\title{
A systematic review of the impact of center volume in dialysis
}

\author{
Dawid Pieper ${ }^{1 *}$, Tim Mathes ${ }^{1}$ and Mark Roger Marshall 2,3,4
}

\begin{abstract}
Background: A significant relationship exists between the volume of surgical procedures that a given center performs and subsequent outcomes. It seems plausible that such a volume-outcome relationship is also present in dialysis.

Methods: MEDLINE and EMBASE were searched in November 2014 for non-experimental studies evaluating the association between center volume and patient outcomes [mortality, morbidity, peritonitis, switch to hemodialysis (HD) or any other treatment], without language restrictions or other limits. Selection of relevant studies, data extraction and critical appraisal were performed by two independent reviewers. We did not perform meta-analysis due to clinical and methodological heterogeneity (e.g. different volume categories).
\end{abstract}

Results: 16 studies met out inclusion criteria. Most studies were performed in the US. The study quality ranged from fair to good. Only few items were judged to have a high risk of bias, while many items were judged to have an unclear risk of bias due to insufficient reporting. All 10 studies that analyzed peritoneal dialysis (PD) technique survival by modeling switch to HD or any other treatment as an outcome showed a statistical significant effect. The relative effect measures ranged from 0.25 to 0.94 (median 0.73 ) in favor of high volume centers. All nine studies indicated a lower mortality for PD in high volume centers, but only study was statistical significant.

Conclusions: This systematic review supports a volume-outcome relationship in peritoneal dialysis with respect to switch to HD or any other treatment. An effect on mortality is probably present in HD. Further research is needed to identify and understand the associations of center volume that are causally related to patient benefit.

Keywords: Dialysis, Hospitals, high volume, Kidney failure, Outcome assessment, Review

\section{Background}

Previous systematic reviews (SR) have shown the presence of a significant relationship between the volume of surgical procedures that a given center performs and subsequent outcomes [1-6]. This so-called volume-outcome relationship is reported to be stronger in high risk, low volume procedures [7-10]. The volume-outcome relationship has also been found outside of surgery [11, 12]. Two hypotheses exist for this relationship. On the one hand, a higher caseload and experience may result in more effective skills ("practice makes perfect"). On the other, providers with better outcomes might receive

\footnotetext{
*Correspondence: dawid.pieper@uni-wh.de

${ }^{1}$ Institute for Research in Operative Medicine, Witten/Herdecke

University, Ostmerheimer Str. 200, Building 38, 51109 Cologne, Germany

Full list of author information is available at the end of the article
}

more referrals thereby increasing their volume ("selective referral") $[13,14]$.

Outcomes in dialysis are very heterogeneous in international research [15-17]. Such differences even remain after adjusting for measured patient characteristics [18]. Acknowledging residual confounding as an ever-present issue, center-related attributes are likely to be the main contributing factor. It is plausible that volume-outcome relationships are causal or intermediate variables on the pathway between center effect and patient outcomes (e.g. mortality risk).

To the best of our knowledge, there is no reported SR on the volume-outcome relationship in dialysis. We also did not find any ongoing SR by checking registries (Cochrane library and PROSPERO). The aim of this SR 
is to examine the effects of center volume, specialization and regionalization on the outcomes in dialysis.

\section{Methods}

We performed a systematic literature search to identify all relevant publications on the relationship between center volume and patient outcomes in dialysis. Medline (via PubMed) and Embase (via Embase) were searched from inception to November 2014 (see Additional file 1: Appendix S1 for search strategies). Reference lists of retrieved articles were inspected to identify additional articles that could have been missed by our search strategy. No language restrictions or other limits were applied.

For consideration in this SR the following inclusion criteria were applied to each publication: the subject of the study was dialysis [either peritoneal dialysis (PD) or hemodialysis (HD)]; the study had a comparative design; patient outcomes (e.g. mortality, morbidity, peritonitis, switch to HD) were studied; volume was defined as a distinct number (e.g. continuous variable) or a cut-off value, or specialized/regionalized centers were analysed; the study did not describe a single center. All titles and abstracts were screened independently by two persons and the full texts of potentially eligible articles were then obtained and further assessed for eligibility against the review inclusion criteria. Any disagreements were resolved by discussion.

Data were extracted by one reviewer into structured summary tables and checked for accuracy by a second reviewer. Any disagreements were discussed until till consensus was reached. For each publication, we extracted data on patient characteristics; setting; data source(s); center volume definition; and results. In accordance with prior SRs investigating the volume-outcome relationship we extracted only the comparison for the highest volume category vs. the lowest volume category, as defined by the study authors. If necessary, effect measures such as odds ratios (OR), risk ratios (RR) or hazard ratios (HR) were recalculated in order to achieve that the results are always presented as comparing high volume centers with low volume centers (and not vice versa). Furthermore, we also calculated relevant effect measures if these were not reported by the study authors, but were available from the text. In case of unadjusted and adjusted analysis presented in the studies, we focused on the adjusted results. At all stages of data selection, data extraction and critical appraisal we contacted authors for clarification, if needed.

Methodological quality of the eligible studies was undertaken independently by two persons. Any disagreements were resolved by discussion. We utilized a quality assessment tool based on the Newcastle-Ottawa-Scale [19] that was recently used in a Cochrane review that investigated the volume-outcome relationship in colorectal cancer [20]. We made some minor adaptations when applying the tool to registry-based studies, around the last two questions dealing with incomplete data and missing data. It is quite likely that many registries might only incorporate data of cases with complete data. Under these circumstances a question on incomplete or missing data would be inappropriate as an assessment of quality. We made a considered judgement to replace these two questions for all registry-based studies, and evaluated the "quality of registry data" and the "selection of patients" instead. Both questions were previously used for a similar question related to the volume-outcome relationship in registry-based studies [12]. For all other studies, we used the original assessment tool from the Cochrane review by Archampong et al. [20], but omitted the first item concerning study design. For this particular clinical question, we deemed it inappropriate to include retrospective study design per se as a criterion for determining degree of bias. In the SR by Archampong et al., all registry-based studies were assessed to have a high risk of bias as a result of their retrospective design, despite the fact that many collect information prospectively. We obtained literature for additional information about the corresponding registries, if referenced by the study authors. Our modified assessment tool can be found in Additional file 2: Appendix S2, which has already been used successfully in a SR investigating the volume-outcome relationship in the Norwood procedure [21].

Because the identified studies were expected to be methodologically diverse (for example, different volume definitions), we decided a priori not to statistically combine results.

A p-level of $<0.05$ was considered statistically significant.

\section{Results}

The search strategy generated 251 hits, of which 16 studies [22-37] met our inclusion criteria (Fig. 1). A list of excluded studies can be found in Additional file 3: Appendix S3. All 16 studies dealt with volume, while one study also contained data on hospital type [23]. In total, there were 15 registry-based studies and one clinical study [36]. Six studies were from the US [24, 25, 27, 34-36], four from France [26, 28, 31, 32], three from Canada [23, 29, 30], and each one study from Brazil [33], the Netherlands [22], and Romania [37]. All French studies were based on data from the French Peritoneal Dialysis Registry (RDPLF) and all Canadian studies were based on the Canadian Organ Replacement Register (CORR). The observation periods varied across all studies with the longest follow-up being 16 years in one study [23]. Similarly, the volume definitions varied extensively and were 


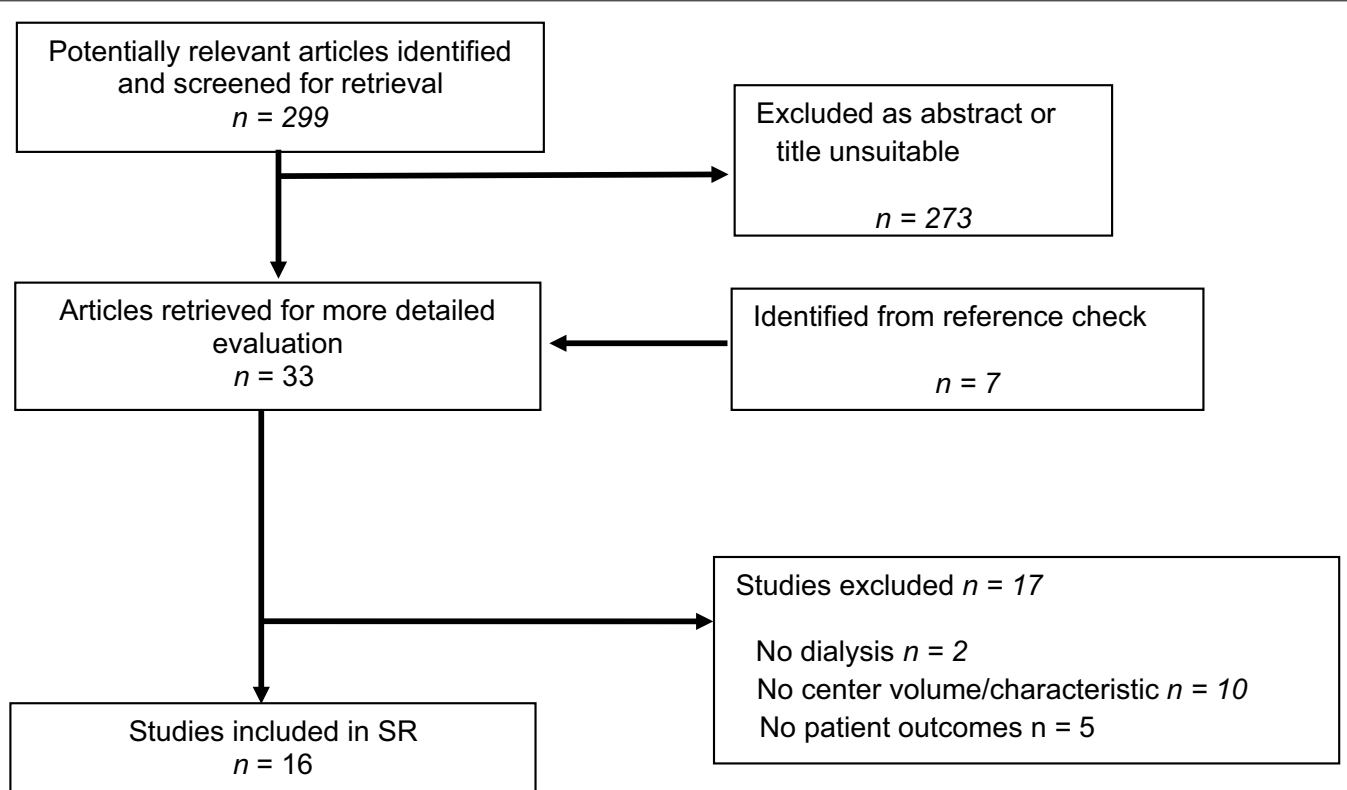

Fig. 1 Flow chart

often not well reported. The number of volume categories ranged from two $[22,24,25,30,36,37]$ to seven [28].

\section{Study quality}

Table 1 summarizes the results of the quality assessment. The study quality ranged from fair to good. There were only few items that were judged to have a high risk of bias. However, many items were judged to have an unclear risk of bias. This was mainly the result of insufficient reporting. In this context, many problems arose in particular when rating the outcome variables. However, it should be noted that an unclear risk of bias should be interpreted taking the character of the outcome variable under study into account. This explains the diverging outcome assessments for mortality and peritonitis, for example. Death as an outcome variable is more reliable than peritonitis. There was each one single best study for PD [28] and HD [27].

\section{Center volume}

\section{$P D$}

Ten studies analyzed PD technique survival by modeling switch to HD or any other treatment as an outcome [22-26, 28, 31, 32, 34, 36]. All studies showed a statistically significant result in favor of high volume facilities (Table 2). The relative effect measures ranged from 0.25 to 0.94 (median 0.73). However, it should be noted that four studies [26, 28, 31, 32] were based on the RDPLF and two $[24,34]$ studies were based on data from the Baxter Healthcare Corporation. Taking the observation periods into account, an overlap of participants will have occurred for both databases, although the overlap is likely to be greater for the RDPLF.

Nine studies analyzed patient survival by modeling mortality risk as an outcome $[22,23,25,26,28,31,32,34$, $36]$. Although the majority of studies indicated a slightly lower mortality or even a null effect for high volume facilities, only one study was able to prove this effect statistically yielding a $R R=0.71$ (95\% CI 0.63-0.81) [23]. This analysis had an observation period from 1981 to 1997. Limiting the observation period from 1990 to 1997 resulted in a stronger effect with a $\mathrm{RR}=0.51(95 \% \mathrm{CI}$ $0.41-0.64$ ).

Among four studies investigating peritonitis as an outcome $[26,31,33,35]$, one study based on data from the Brazilian Peritoneal Dialysis Study revealed lower rates of peritonitis in high volume centers yielding a $\mathrm{HR}=0.67$ (95\% CI 0.46-0.98) [33]. The other studies did not reach statistical significance.

$H D$

One large study found patients on HD treated in high volume facilities to survive longer [27]. The unadjusted OR for 1 year survival was 1.24 (95 \% CI 1.21-1.28) when high volume facilities were compared to low volume facilities. The OR increased to 1.29 (95\% CI 1.26-1.32) for 4 year survival. Adjusted analyses were performed for patients with and without diabetes as their primary cause of end stage renal disease (ESRD). Statistical significant HRs were found in both groups per 10 unit increase. 
Table 1 Study quality

\begin{tabular}{|c|c|c|c|c|c|c|c|c|}
\hline \multirow[t]{2}{*}{ Study } & \multirow{2}{*}{$\begin{array}{l}\text { Representa- } \\
\text { tiveness }\end{array}$} & \multirow{2}{*}{$\begin{array}{l}\text { Ascertain- } \\
\text { ment }\end{array}$} & \multirow{2}{*}{$\begin{array}{l}\text { Compara- } \\
\text { bility }\end{array}$} & \multicolumn{3}{|l|}{ Outcome } & \multirow{2}{*}{$\begin{array}{l}\text { Registry quality/ } \\
\text { addressing } \\
\text { incomplete data }\end{array}$} & \multirow{2}{*}{$\begin{array}{l}\text { Selection/ } \\
\text { missing data } \\
\text { on primary } \\
\text { interventions } \\
\text { and outcomes }\end{array}$} \\
\hline & & & & $\begin{array}{l}\text { Mortality/ } \\
\text { survival }\end{array}$ & $\begin{array}{l}\text { Switch } \\
\text { to HD/other } \\
\text { treatment }\end{array}$ & Peritonitis & & \\
\hline Afolalu 2009 [25] & - & + & - & + & $?$ & NA & $?$ & - \\
\hline Castrale 2010 [26] & - & $?$ & + & + & $?$ & $?$ & + & + \\
\hline Eisenstein 2008 [27] & + & + & + & + & NA & NA & - & + \\
\hline Evans 2013 [28] & + & + & + & + & + & NA & + & + \\
\hline Fenton 1997 [29] & + & + & + & + & NA & NA & $?$ & $?$ \\
\hline Fenton 1993 [30] & - & $?$ & $?$ & + & NA & NA & $?$ & - \\
\hline $\begin{array}{l}\text { Guo } \\
2003[24]\end{array}$ & + & $?$ & + & NA & $?$ & NA & $?$ & - \\
\hline Huisman 2002 [22] & + & $?$ & $?$ & + & $?$ & NA & + & + \\
\hline Lobbedez 2011 [31] & - & + & + & NA & $?$ & $?$ & + & $?$ \\
\hline Lobbedez 2013 [32] & + & + & + & + & $?$ & NA & + & - \\
\hline Martin 2011 [33] & + & + & + & NA & NA & $?$ & $?$ & + \\
\hline Mircescu 2014 [37] & + & $?$ & + & + & NA & NA & $?$ & $?$ \\
\hline Mujais 2006 [34] & $?$ & $?$ & $?$ & NA & $?$ & NA & $?$ & $?$ \\
\hline Nolph 1986 [35] & - & $?$ & $?$ & NA & NA & $?$ & + & $?$ \\
\hline Plantinga 2009 [36] & + & + & $?$ & + & $?$ & NA & $?$ & $?$ \\
\hline Schaubel 2001 [23] & + & $?$ & + & + & $?$ & NA & $?$ & $?$ \\
\hline
\end{tabular}

+ , fulfilled; ?, unclear; -, not fulfilled; $N A$, not applicable

\section{$P D$ and $H D$}

Two studies analysed data from the CORR. One study found a statistically significant lower mortality $(\mathrm{RR}=0.85 ; 95 \% \mathrm{CI} 0.78-0.91)$ in high volume hospitals [30]. The second study included only patients older than 64 years and resulted in a very similar effect yielding a $R R=0.84(p=0.07)$ but failed to reach statistical significance [29]. A third study for Romania found an adjusted HR of 0.88 (95\% CI 0.81-0.97) [37].

\section{Discussion}

This article reviewed the existing literature on the volume-outcome relationship in dialysis. PD was studied most intensively. Therein, the majority of studies investigated either patient survival or technique survival as outcomes. With respect to PD, center volume has an effect on technique survival only. There was no effect on mortality risk or patient survival, while the evidence for peritonitis is inconclusive due to a limited number of studies. There is also not much evidence for HD, where only one study was available. Not withstanding, that study did show a strong effect of center volume on mortality. Studies analysing PD and HD together seem to support this finding. It can be concluded, that regarding mortality, there is no associated volume-outcome relationship in PD, but possibly in HD. No patient outcomes other than mortality have been studied for HD and HD/PD. Center type has only been investigated in one study, making it impossible to draw definitive conclusions.

\section{Limitations of the included studies}

A number of methological issues impede consistent interpretation of the included studies. All studies are non-experimental raising questions in particular with respect to quality and completeness of data. Center volume as an explanatory variable can be confusing as the number of treated patients may classify the same center as either low volume or high volume, depending on geopolitical context. Center volume was defined in a number of different ways for all of our included studies. This is contrasts with surgical literature, where definitions of volume are more consistent yielding comparable results and providing convergent validity [38].

The time-varying nature of center volume as it pertains to dialysis is also problematic. For surgical procedures, patients undergo an operation and perhaps an inpatient stay depending on their requirements for recovery. Volume is modelled by annual caseloads, taking center volume either in the same year of patient's admission [39] or 1 year before [40]. The temporal relationship between volume and outcome is therefore close. In contrast, ESRD is a chronic disease requiring indefinite treatment, with outcomes measured and reported over prolonged periods. Given the organic growth in ESRD, patient volumes 


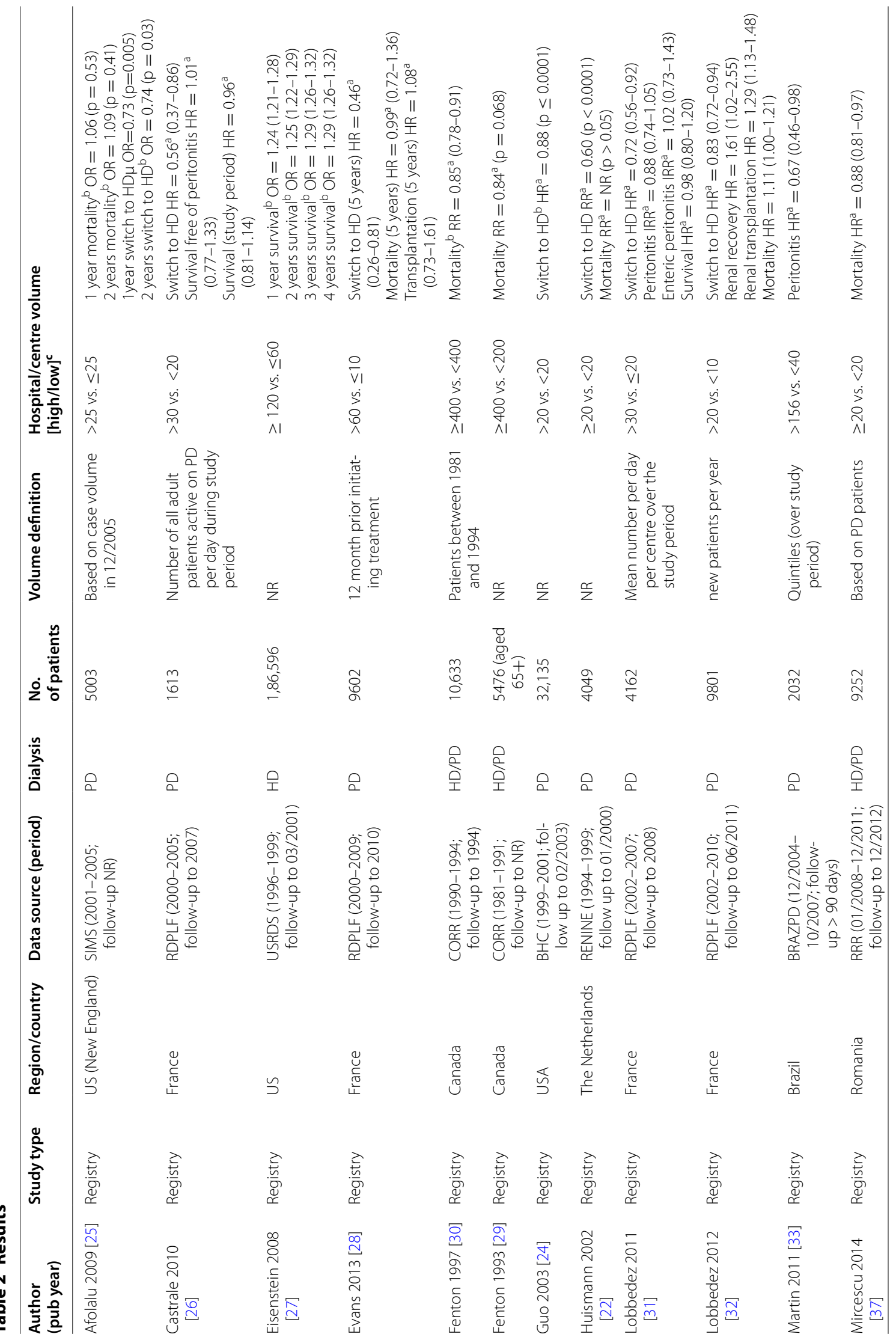




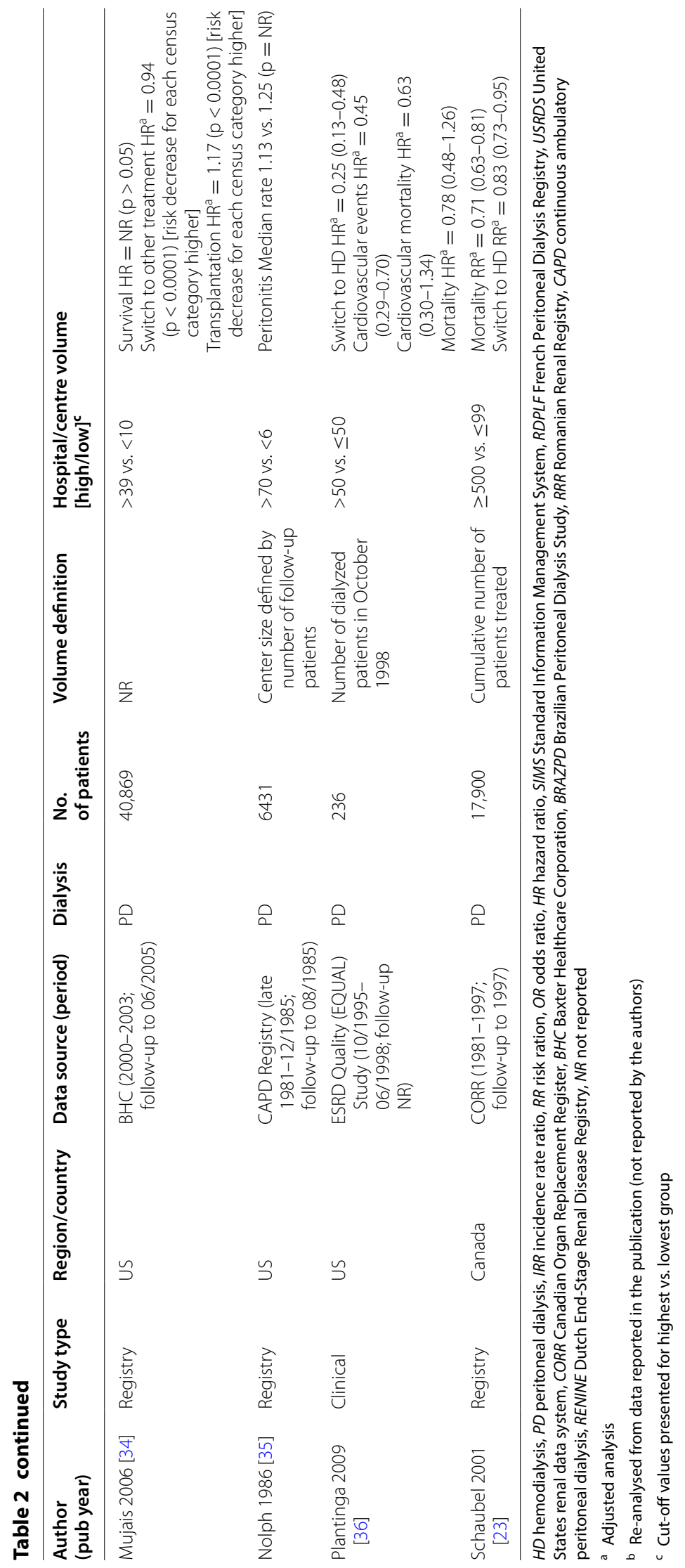


are likely to vary and most likely increase over time in a given centre. If studies are performed over a prolonged period of observation, associations may be potentially biased by the use of baseline values for centre volume, or weakened if the authors take the mean over the whole study period.

In general, the authors of the included studies failed to justify their rationale for definition and categorization of centre volume. We cannot presume that their modelling choices were data driven, and many appear arbitrary. Interestingly, we found all studies analyzing volume as a categorical variable. There are advantages and disadvantages to this approach. Categorization of continuous data does avoid the presumption of any mathematical relationship, but can obscure associations and prevent deep understanding of data [41-43]. Prior research has shown that the volume-outcome relationship in surgery can be linear, stepwise, curvelinear or U-shaped, for example [44-47], and this requires further elucidation for dialysis.

As the included studies were observational, appropriate adjustment for possible confounders is critical. This is particularly relevant for studies investigating the volume-outcome relationship [48, 49]. All of the included studies made adjustments as possible, but were limited by data availability. A large but unquantifiable degree of residual confounding is therefore likely from omitted known patient-level and centre-level risk factors [15-18, $50-55]$.

\section{Limitations of the review}

We acknowledge that our work has some limitations. First, we did not search for grey literature. This might have yielded additional information. However, we have cross-checked the references of all included studies and were able to include three studies that were not retrieved by our search strategy. Publication bias is difficult to assess. It should be noted that there are many dialysis registries available worldwide. Thus it is likely that more evidence could be produced within a short time from ongoing analysing at these registries.

Our systematic review did not aim to provide cut-off values. Cut-off values could be extended to minimum volume standards. Such standards already exist in surgery, but are well justified by robust volume-outcome data [56-60]. In dialysis, there are not only philosophical challenges as discussed, but also methodological issues to defining cut-off volumes that have not yet been explored in this area [61]. The contextual limitations of the included studies precluded us from defining or even suggesting cut-off values.

A point to note is that we did not use a validated tool to appraise study quality, but instead developed our own tool based on one from a previous Cochrane review. The rationale for this is that there is no tool that can be considered the 'gold standard' for this kind of clinical question/study designs. However, the quality assessment of a registry-based study remains challenging, resulting in numerous studies where the items could not be assessed as the publications provided no information on it. We have already faced this problem in an earlier SR [21]. Although there is much literature related to the quality of registries [62, 63], there is no accepted critical appraisal tool for registry-based studies or for registry-based studies specific items. The idea of a registry of registries has already been suggested [64], and this might be helpful for future SRs based on registry-based studies. Reporting standards for registry-based studies would further encourage authors to report relevant information to facilitate the assessment of the methodological quality.

This systematic review focused only on center volume or center type effects. As for many surgical procedures and other medical conditions, it is also possible to focus on the physician volume. One recent study found that nephrologists with the lowest patient mortality rates had significantly lower patient caseloads than nephrologists with the highest mortality rates [65].

\section{Conclusion}

In conclusion, this systematic review supports a volumeoutcome relationship in PD with respect to switch to HD or any other treatment. An effect on mortality is probably present in HD. Center volume itself can only be regarded as a proxy for quality of care, and further research is needed to identify the associations of center volume that are causally related to patient benefit. There is a surprising dearth of literature in the area, and such data would be valuable for quality initiatives in order to help identified low performing centers achieve better outcomes for their patients.

\section{Additional files}

Additional file 1: Appendix S1. Search strategy.

Additional file 2: Appendix S2. Critical appraisal tool.

Additional file 3: Appendix S3. List of excluded studies.

\section{Abbreviations}

RDPLF: French Peritoneal Dialysis Registry; HR: hazard ratio; HD: hemodialysis; OR: odds ratio; PD: peritoneal dialysis; RR: risk ratio; SR: systematic review.

\section{Authors' contributions}

DP conceptualized and designed the study, searched for literature, extracted and analyzed data, drafted the initial manuscript, and approved the final

manuscript as submitted. TM searched for literature, extracted data and analyzed data, and approved the final manuscript as submitted. MM analyzed and interpreted data, critically reviewed the manuscript, and approved the final manuscript as submitted. All authors read and approved the final manuscript. 


\section{Author details}

${ }^{1}$ Institute for Research in Operative Medicine, Witten/Herdecke University, Ostmerheimer Str. 200, Building 38, 51109 Cologne, Germany. ${ }^{2}$ Faculty of Medical and Health Sciences, University of Auckland, Auckland, New Zealand. ${ }^{3}$ Department of Renal Medicine, Counties Manukau, Health, Auckland, New Zealand. ${ }^{4}$ Baxter Healthcare (Asia Pacific), Shanghai, People's Republic of China.

\section{Competing interests}

D.P. and T.M. have no Competing interest. M.M. has received honoraria as an advisor to Abbott Australia Pty Ltd. and travel grants from Roche Products NZ Ltd., Novartis NZ Ltd., and Fresenius Medical Care-Asia-Pacific Pty Ltd. He is employed by Baxter Healthcare (Asia-Pacific) Ltd.

\section{Received: 30 November 2015 Accepted: 1 December 2015} Published online: 22 December 2015

\section{References}

1. Gooiker GA, Van Gijn W, Post PN, Van De Velde CJH, Tollenaar RAEM, Wouters MWJM. A systematic review and meta-analysis of the volumeoutcome relationship in the surgical treatment of breast cancer. Are breast cancer patients better of with a high volume provider? Eur J Surg Oncol. 2010;36(Suppl. 1):S27-35.

2. Gooiker GA, Van Gijn W, Wouters MWJM, Post PN, Van De Velde CJH, Tollenaar RAEM. Systematic review and meta-analysis of the volume-outcome relationship in pancreatic surgery. Br J Surg. 2011;98(4):485-94.

3. Goossens-Laan CA, Gooiker GA, Van Gijn W, Post PN, Bosch JLHR, Kil PJM, et al. A systematic review and meta-analysis of the relationship between hospital/surgeon volume and outcome for radical cystectomy: an update for the ongoing debate. Eur Urol. 2011;59(5):775-83.

4. Van Gijn W, Gooiker GA, Wouters MWJM, Post PN, Tollenaar RAEM, Van De Velde CJH. Volume and outcome in colorectal cancer surgery. Eur J Surg Oncol. 2010;36(Suppl. 1):S55-63.

5. van Heek NT, Kuhlmann KF, Scholten RJ, de Castro SM, Busch OR, van Gulik TM, et al. Hospital volume and mortality after pancreatic resection: a systematic review and an evaluation of intervention in the Netherlands. Ann Surg. 2005;242(6):781-8.

6. Wouters MWJM, Gooiker GA, Van Sandick JW, Tollenaar RAEM. The volume-outcome relation in the surgical treatment of esophageal cancer: a systematic review and meta-analysis. Cancer. 2012;118(7):1754-63.

7. Birkmeyer JD, Dimick JB, Staiger DO. Operative mortality and procedure volume as predictors of subsequent hospital performance. Ann Surg. 2006;243(3):411-7.

8. Birkmeyer JD, Siewers AE, Marth NJ, Goodman DC. Regionalization of high-risk surgery and implications for patient travel times. JAMA. 2003;290(20):2703-8.

9. Birkmeyer JD, Siewers AE, Finlayson EV, Stukel TA, Lucas FL, Batista I, et al. Hospital volume and surgical mortality in the United States. N Engl J Med. 2002;346(15):1128-37.

10. Pieper D, Mathes T, Neugebauer E, Eikermann M. State of evidence on the relationship between high-volume hospitals and outcomes in surgery: a systematic review of systematic reviews. J Am Coll Surg. 2013;216(5):1015-1025.e18.

11. Wells G, Shea B, O'Connell D, Peterson J, Welch V, Losos M, et al. http:// www.ohri.ca/programs/clinical_epidemiology/oxford.asp. Accessed 10 Apr 2014.

12. Institute for Quality and Efficiency in Health Care (IQWiG). Zusammenhang zwischen der Menge der erbrachten Leistungen und der Ergebnisqualität für die Indikation "Elektiver Eingriff Bauchaortenaneurysma". 2006.

13. Luft HS. The relation between surgical volume and mortality: an exploration of causal factors and alternative models. Med Care. 1980;18(9):940-59.

14. Luft HS, Hunt SS, Maerki SC. The volume-outcome relationship: practice-makes-perfect or selective-referral patterns? Health Serv Res. 1987;22(2):157-82.

15. Blank L, Peters J, Lumsdon A, O'Donoghue DJ, Feest TG, Scoble J, et al. Regional differences in the provision of adult renal dialysis services in the UK. QJM. 2005;98(3):183-90.
16. Devereaux PJ, Schunemann HJ, Ravindran N, Bhandari M, Garg AX, Choi PT, et al. Comparison of mortality between private for-profit and private not-for-profit hemodialysis centers: a systematic review and meta-analysis. JAMA. 2002;288(19):2449-57.

17. Hommel K, Rasmussen S, Kamper AL, Madsen M. Regional and social inequalities in chronic renal replacement therapy in Denmark. Nephrol Dial Transplant. 2010;25(8):2624-32.

18. McClellan WM, Flanders WD, Gutman RA. Variable mortality rates among dialysis treatment centers. Ann Intern Med. 1992;117(4):332-6.

19. Wells G, Shea B, O'Connell D, Peterson J, Welch V, Losos M, et al. The Newcastle-Ottawa Scale (NOS) for assessing the quality of non randomised studies in meta-analyses. Accessed 10 Apr 2014. http://www.ohri.ca/ programs/clinical_epidemiology/oxford.asp.

20. Archampong D, Borowski D, Wille-Jorgensen P, Iversen LH. Workload and surgeon's specialty for outcome after colorectal cancer surgery. Cochrane Database Syst Rev. 2012;3:CD005391.

21. Pieper D, Mathes T, Asfour B. A systematic review of the impact of volume of surgery and specialization in Norwood procedure. BMC Pediatr. 2014;14:198.

22. Huisman RM, Nieuwenhuizen MG, Th de Charro F. Patient-related and centre-related factors influencing technique survival of peritoneal dialysis in The Netherlands. Nephrol Dial Transplant. 2002;17(9):1655-60.

23. Schaubel DE, Blake PG, Fenton SS. Effect of renal center characteristics on mortality and technique failure on peritoneal dialysis. Kidney Int. 2001;60(4):1517-24

24. Guo A, Mujais S. Patient and technique survival on peritoneal dialysis in the United States: evaluation in large incident cohorts. Kidney Int Suppl. 2003;88:S3-12.

25. Afolalu B, Troidle L, Osayimwen O, Bhargava J, Kitsen J, Finkelstein FO. Technique failure and center size in large cohort of peritoneal dialysis patients in a defined geographic area. Perit Dial Int. 2009;29(3):292-6.

26. Castrale C, Evans D, Verger C, Fabre E, Aguilera D, Ryckelynck JP, et al. Peritoneal dialysis in elderly patients: report from the French Peritoneal Dialysis Registry (RDPLF). Nephrol Dial Transplant. 2010;25(1):255-62.

27. Eisenstein EL, Sun JL, Anstrom KJ, Stafford JA, Szczech LA, Muhlbaier LH, et al. Re-evaluating the volume-outcome relationship in hemodialysis patients. Health policy. 2008;88:317-25.

28. Evans D, Lobbedez T, Verger C, Flahault A. Would increasing centre volumes improve patient outcomes in peritoneal dialysis? A registry-based cohort and Monte Carlo simulation study. BMJ Open. 2013;3(6):e003092.

29. Fenton SS, Desmeules M, Jeffery JR, Corman JL. Dialysis therapy among elderly patients; data from the Canadian Organ Replacement Register, 1981-1991. Adv Perit Dial. 1993;9:124-9.

30. Fenton SSA, Schaubel DE, Desmeules M, Morrison HI, Mao Y, Copleston P, et al. Hemodialysis versus peritoneal dialysis: a comparison of adjusted mortality rates. Am J Kidney Dis. 1997;30(3):334-42.

31. Lobbedez T, Touam M, Evans D, Ryckelynck JP, Knebelman B, Verger C. Peritoneal dialysis in polycystic kidney disease patients. Report from the French peritoneal dialysis registry (RDPLF). Nephrol Dial Transplant. 2011;26(7):2332-9.

32. Lobbedez T, Verger C, Ryckelynck JP, Fabre E, Evans D. Is assisted peritoneal dialysis associated with technique survival when competing events are considered? Clin J Am Soc Nephrol. 2012;7(4):612-8

33. Martin LC, Caramori JCT, Fernandes N, Divino-Filho JC, Pecoits-Filho R, Barretti P. Geographic and educational factors and risk of the first peritonitis episode in Brazilian peritoneal dialysis study (BRAZPD) patients. Clin J Am Soc Nephrol. 2011;6(8):1944-51.

34. Mujais S, Story K. Peritoneal dialysis in the US: evaluation of outcomes in contemporary cohorts. Kidney Int. 2006;70(Suppl. 103):S21-6.

35. Nolph KD, Cutler SJ, Steinberg SM, Novak JW. Special studies from the NIH USA CAPD registry. Perit Dial Bull. 1986;6(1):28-34.

36. Plantinga LC, Fink NE, Finkelstein FO, Powe NR, Jaar BG. Association of peritoneal dialysis clinic size with clinical outcomes. Perit Dial Int. 2009:29(3):285-91.

37. Mircescu G, Stefan G, Garneata L, Mititiuc I, Siriopol D, Covic A. Outcomes of dialytic modalities in a large incident registry cohort from Eastern Europe: the Romanian renal registry. Int Urol Nephrol. 2014;46(2):443-51.

38. Kulkarni GS, Laupacis A, Urbach DR, Fleshner NE, Austin PC. Varied definitions of hospital volume did not alter the conclusions of volume-outcome analyses. J Clin Epidemiol. 2009;62(4):400-7. 
39. Ho V. Evolution of the volume-outcome relation for hospitals performing coronary angioplasty. Circulation. 2000;101(15):1806-11.

40. Hamilton $\mathrm{BH}, \mathrm{Ho}$ V. Does practice make perfect? Examining the relationship between hospital surgical volume and outcomes for hip fracture patients in Quebec. Med Care. 1998;36(6):892-903.

41. Altman DG, Royston P. The cost of dichotomising continuous variables. BMJ. 2006;332(7549):1080.

42. Royston P, Altman DG, Sauerbrei W. Dichotomizing continuous predictors in multiple regression: a bad idea. Stat Med. 2006;25(1):127-41.

43. Wand H, Ramjee G. Analyzing continuous measures in HIV prevention research using semiparametric regression and parametric regression models: how to use data to get the (right) answer? AIDS Behav. 2012;16(6):1448-53.

44. Abbenbroek B, Duffield CM, Elliott D. The intensive care unit volumemortality relationship, is bigger better? An integrative literature review. Aust Crit Care. 2014;27(4):157-64.

45. Harrysson IJ, Cook J, Sirimanna P, Feldman LS, Darzi A, Aggarwal R. Systematic review of learning curves for minimally invasive abdominal surgery: a review of the methodology of data collection, depiction of outcomes, and statistical analysis. Ann Surg. 2014;260(1):37-45.

46. Ramsay CR, Grant AM, Wallace SA, Garthwaite PH, Monk AF, Russell IT. Statistical assessment of the learning curves of health technologies. Health Technol Assess. 2001;5(12):1-79.

47. Sund R. Modeling the volume-effectiveness relationship in the case of hip fracture treatment in Finland. BMC Health Serv Res. 2010;10:238.

48. Christian CK, Gustafson ML, Betensky RA, Daley J, Zinner MJ. The volumeoutcome relationship: don't believe everything you see. World I Surg. 2005;29(10):1241-4

49. Halm EA, Lee C, Chassin MR. Is volume related to outcome in health care? A systematic review and methodologic critique of the literature. Ann Intern Med. 2002;137(6):511-20.

50. United States Renal Data System (USRDS). Annual data report 2013: Atlas of chronic kidney disease and end-stage renal disease in the United States. Rockville: Bethesda; 2013.

51. Fabrizi F, Dixit V, Messa P. Impact of hepatitis $C$ on survival in dialysis patients: a link with cardiovascular mortality? J Viral Hepat. 2012;19(9):601-7.

52. Zhang W, He J, Zhang F, Huang C, Wu Y, Han Y, et al. Prognostic role of $C$-reactive protein and interleukin- 6 in dialysis patients: a systematic review and meta-analysis. J Nephrol. 2013;26(2):243-53.
53. Griva K, Lai AY, Lim HA, Yu Z, Foo MW, Newman SP. Non-adherence in patients on peritoneal dialysis: a systematic review. PLoS One. 2014;9(2):e89001.

54. Heerspink HJ, Ninomiya T, Zoungas S, de Zeeuw D, Grobbee DE, Jardine MJ, et al. Effect of lowering blood pressure on cardiovascular events and mortality in patients on dialysis: a systematic review and meta-analysis of randomised controlled trials. Lancet. 2009;373(9668):1009-15.

55. Vonesh EF, Snyder JJ, Foley RN, Collins AJ. The differential impact of risk factors on mortality in hemodialysis and peritoneal dialysis. Kidney Int. 2004;66(6):2389-401.

56. Massarweh NN, Flum DR, Symons RG, Varghese TK, Pellegrini CA. A critical evaluation of the impact of Leapfrog's evidence-based hospital referral. J Am Coll Surg. 2011;212(2):150-159.e1.

57. Simunovic M, Urbach D, Major D, Sutradhar R, Baxter N, To T, et al. Assessing the volume-outcome hypothesis and region-level quality improvement interventions: pancreas cancer surgery in two Canadian Provinces. Ann Surg Oncol. 2010;17(10):2537-44.

58. Ho V. Certificate of need, volume, and percutaneous transluminal coronary angioplasty outcomes. Am Heart J. 2004;147(3):442-8.

59. Ohmann C, Verde PE, Blum K, Fischer B, de Cruppe W, Geraedts M. Two short-term outcomes after instituting a national regulation regarding minimum procedural volumes for total knee replacement. J Bone Joint Surg Am. 2010;92(3):629-38.

60. Geraedts M, de Cruppe W, Blum K, Ohmann C. Implementation and effects of Germany's minimum volume regulations: results of the accompanying research. Dtsch Arztebl Int. 2008;105(51-52):890-6.

61. Grouven U, Kuchenhoff H, Schrader P, Bender R. Flexible regression models are useful tools to calculate and assess threshold values in the context of minimum provider volumes. J Clin Epidemiol. 2008;61(11):1125-31.

62. Arts DG, De Keizer NF, Scheffer GJ. Defining and improving data quality in medical registries: a literature review, case study, and generic framework. J Am Med Inform Assoc. 2002;9(6):600-11.

63. Registries for evaluating patient outcomes: a user's guide. In: Gliklich RE, Dreyer NA, Leavy MB, editors. Rockville: Rockville (MD); 2014.

64. Heger M. A registry of registries? The US backs the idea for patients. Nat Med. 2011;17(1):4. doi:10.1038/nm0111-4a.

65. Harley KT, Streja E, Rhee CM, Molnar MZ, Kovesdy CP, Amin AN, et al. Nephrologist caseload and hemodialysis patient survival in an urban cohort. J Am Soc Nephrol. 2013;24(10):1678-87.

\section{Submit your next manuscript to BioMed Central and we will help you at every step:}

- We accept pre-submission inquiries

- Our selector tool helps you to find the most relevant journal

- We provide round the clock customer support

- Convenient online submission

- Thorough peer review

- Inclusion in PubMed and all major indexing services

- Maximum visibility for your research

Submit your manuscript at www.biomedcentral.com/submit

\section{Biomed Central}

